\title{
Monitoring Chromia/Alumina Catalysts in Situ during Propane Dehydrogenation by Optical Fiber UV-Visible Diffuse Reflectance Spectroscopy
}

\author{
R iikka L. Puurunen, ${ }^{1}$ Bram G. B eheydt, and Bert M. Weckhuysen ${ }^{2}$ \\ Centrum voor O ppervlaktechemie en K atalyse, D epartement I nterfasechemie, K.U. L euven, K asteel park A renberg 23, B-3001 H everlee, B elgium
}

R eceived June 4, 2001; revised A ugust 3, 2001; accepted A ugust 4, 2001

A continuous-flow reactor system with in situ monitoring of the catalyst was developed. The catalyst surface was analyzed by collecting U V-visible diffuse reflectance spectra through an optical fiber placed in the catalyst bed. The system was tested with a series of chromia/alumina catalysts $(1 \mathrm{wt} \% \mathrm{Cr}$ ) under the conditions of propane dehydrogenation. The fast reduction of $\mathrm{Cr}^{6+}$ to $\mathrm{Cr}^{3+}$ under propane stream could be detected. Increase in the catalytic activity with thealumina pretreatment temperature was tentatively ascribed to the presence of $\theta$-alumina, and decrease in the activity during calcination to incorporation of $\mathrm{Cr}^{3+}$ inside the alumina support. (c) 2001 A cademic Press

Key Words: alkane dehydrogenation; catalyst deactivation; chromium; diffuse reflectance spectroscopy; fiber optics.

\section{INTRODUCTION}

M onitoring the events taking place in solid catalysts under operating conditions is crucial for understanding the reaction mechanism of many important chemical processes (1-3). Techniques have been developed which allow the studying of catalysts truly in situ, i.e., at high temperatures and pressures in a stream of reactants. The most used techniques have been infrared spectroscopy (4), R aman spectroscopy $(5,6)$, M össbauer spectroscopy (7), nuclear magnetic resonance spectroscopy $(8,9), X$-ray absorption spectroscopy (10-12), and U V-visible (vis) spectroscopy (13-15). A challenge often remaining is the implementation of the techniques without changing the catalytic properties of the system under study.

\footnotetext{
${ }^{1}$ To whom correspondence should be addressed. Present address: H elsinki U niversity of Technology, Laboratory of Industrial Chemistry, P.O. B ox 6100, FIN-02015 HUT, Finland. Fax: +358-9-451-2622. E-mail: riikka.puurunen@hut.fi.

2 Present address: D epartment of Inorganic Chemistry and Catalysis, D ebye Institute, U trecht U niversity, Sorbonnelaan 16, 3508 TB U trecht, The N etherlands.
}

The current note introduces a new approach for measuring U V-vis diffuse reflectance (DR ) spectra of an operating catalyst. The technique is based on the use of optical fiber technology, by which the state of solid transition metal oxide catalysts can be probed while they are positioned as a fixed bed in a catalytic reactor. Fiberoptic D R spectroscopy has been used for a variety of applications, such as pigment analysis (16), clinical diagnosis (17), and powder blend quality control (18); but to our best knowledge, the current work presents the first application in the field of heterogeneous catalysis. A s an example, the changes taking place in chromia/alumina catalysts during alkane dehydrogenation are monitored by U V-vis D R spectroscopy. A Ikane dehydrogenation is an industrially important process that is a viable route, for example, for the production of high-purity propene used for the production of polymer materials (19). The effect of alumina pretreatment temperature for the catalytic activity is studied. In addition, the differences in activity caused by a deactivating thermal treatment of chromia/alumina catalysts are investigated by in situ U V-vis D R measurements. Finally, the performance of the current setup as an in situ tool is compared with that of a system reported earlier $(13,15)$, and differences are pointed out.

\section{METHODS}

Chromia/alumina catalysts with about 1 wt\% $\mathrm{Cr}$ were prepared by incipient wetness impregnation. A $n$ aqueous solution of $\mathrm{CrO}_{3}$ (U CB Chemicals) was impregnated onto a commercial A K ZO 001-1.5E alumina material that had been pretreated in ambient air at 600,800 , or $1000^{\circ} \mathrm{C}$ for $16 \mathrm{~h}$. B E T surface areas of 235,177 , and $154 \mathrm{~m}^{2} / \mathrm{g}$ were measured for the alumina supports, respectively. The catalysts were aged and dried at 60 and $120^{\circ} \mathrm{C}$ for $4 \mathrm{~h}$, after which they were calcined at $600^{\circ} \mathrm{C}$ for $16 \mathrm{~h}$ or at temperatures up to $1200^{\circ} \mathrm{C}$ for $24 \mathrm{~h}$. The higher calcination temperatures were used to deliberately deactivate the catalysts. 


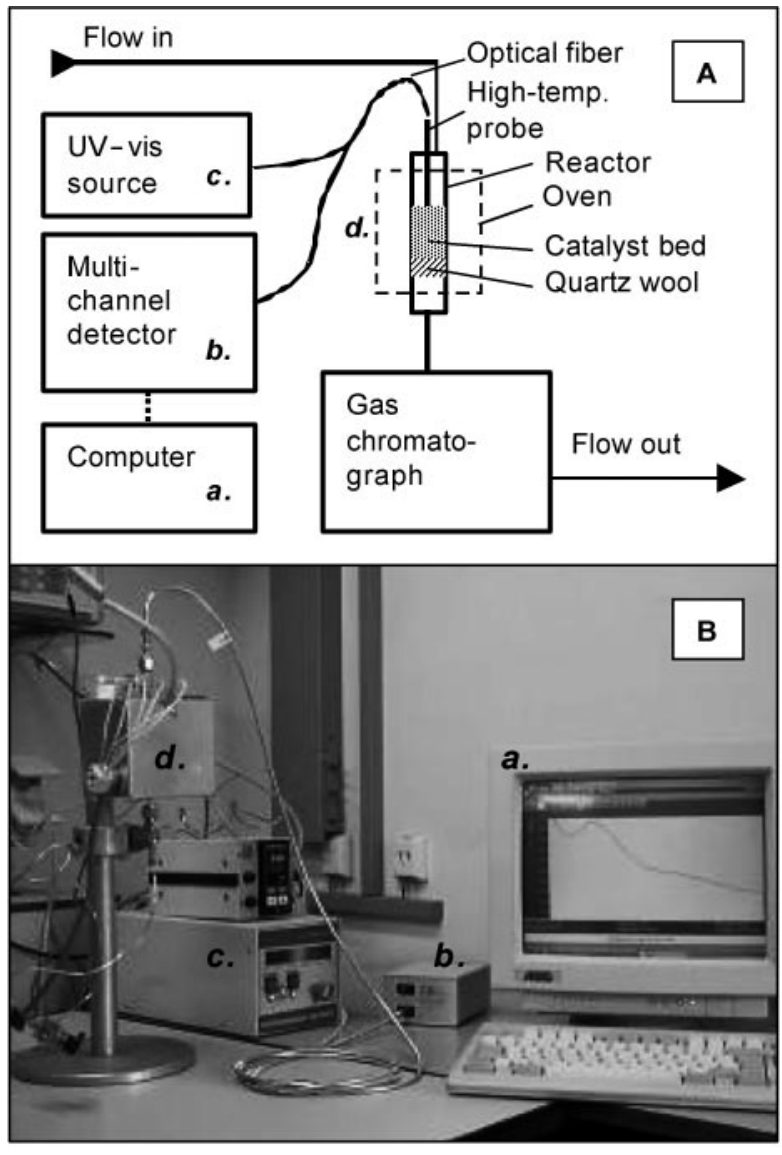

FIG. 1. The fiber-optic UV-visible(vis) spectrometer-reactor setup: (A) a schematic representation and (B) a photographic illustration.

Propane dehydrogenation was carried out at $580^{\circ} \mathrm{C}$ with a $25 \mathrm{ml} / \mathrm{min}$ feed of $10 \mathrm{vol} \%$ propane (A Iphagas, $99.95 \mathrm{vol} \%$ ) in helium ( $\mathrm{A}$ ir Liquide, $99.995 \mathrm{vol} \%$ ) and $0.2 \mathrm{~g}$ of catalyst for $20 \mathrm{~min}$. The catalysts were regenerated for $40 \mathrm{~min}$ by a $25 \mathrm{ml} / \mathrm{min}$ stream of $5 \%$ oxygen (A ir Liquide, $99.5 \mathrm{vol} \%$ ) in helium. A helium flush of $30 \mathrm{~min}$ separated the dehydrogenation and regeneration steps. Three dehydrogenation cycles were carried out. The outlet gases were analyzed on line by a gas chromatograph (G C) (H P 5830A) equipped with a flame ionization detector and a packed column ( $n$ octane/Porasil C). The reported activities correspond to the second cycle after 17.1 min of propane on stream unless otherwise stated. $Y$ ields and selectivities were calculated on a molar basis.

The catalysts were continuously monitored by optical fiber U V-vis D R spectroscopy. A schematic representation of the current setup is shown in Fig. $1 A$ and a photographic illustration in Fig. 1B. The setup consists of a tubular fixedbed reactor fitted inside a furnace, a U V-vis (deuteriumhalogen) light source (Top Sensor Systems D H -2000) and a photodio de array detector (O cean O ptics SD -2000) connected to the catalyst bed via optical fiber technology (Top Sensor SystemsF C B -U V 400-M E cableand F CB -U V 400G -
0.1-X H T high-temperature probe). The high-temperature probe is separated by a few millimetersfrom the hot catalyst particles placed in the fixed-bed reactor. A spectrum of the catalyst in the 200 to $800 \mathrm{~nm}$ region can be collected in less than a second.

$X$-ray diffractograms were measured for some samples with a Siemens D 5000 X -ray Diffractometer. To investigate whether $\mathrm{N}$ a diffuses to the surfaces of samples during the heat treatment, alumina samples pretreated in air at $600,800,1000$, and $1200^{\circ} \mathrm{C}$ were analyzed by X-ray photoelectron spectroscopy (XPS). The XPS data were obtained with a Vacuum Generators XPS system, using a CLAM-2 hemispherical analyzer for electron detection. Non-monochromatic A I K $\alpha$ X-ray radiation was used for exciting the photoelectron spectra using an anode current of $20 \mathrm{~mA}$ at $10 \mathrm{keV}$. The pass energy of the analyzer was set at $50 \mathrm{eV}$, and data were collected at intervals of $0.1 \mathrm{eV}$. Survey spectra were taken with a pass energy of $100 \mathrm{eV}$ at intervals of $0.5 \mathrm{eV}$.

\section{RESULTS AND DISCUSSION}

The yield of propene for the series of chromia/alumina catalysts, where the alumina pretreatment temperature and the catalyst calcination temperature were varied, is shown in Fig. 2. The data points (17.1 min on stream) represent a "stable" situation of the catalysts, where all the $\mathrm{Cr}^{6+}$ has been converted to $\mathrm{Cr}^{3+}$ and the initial $\mathrm{CO}_{2}, \mathrm{CO}$, and $\mathrm{H}_{2} \mathrm{O}$ formation (20) no longer affects the product distribution. Increasing the alumina pretreatment temperature had a positive effect on the dehydrogenation activity of the catalysts. This possibly was caused by the increased formation of the $\theta$-alumina phase during the pretreatment, as was observed by $X$-ray diffraction. $\alpha$-alumina had not yet been formed in the pretreatment at $1000^{\circ} \mathrm{C}$. I ncreasing the calcination temperature of the chromia/alumina catalysts above $600^{\circ} \mathrm{C}$ resulted in loss of dehydrogenation activity.

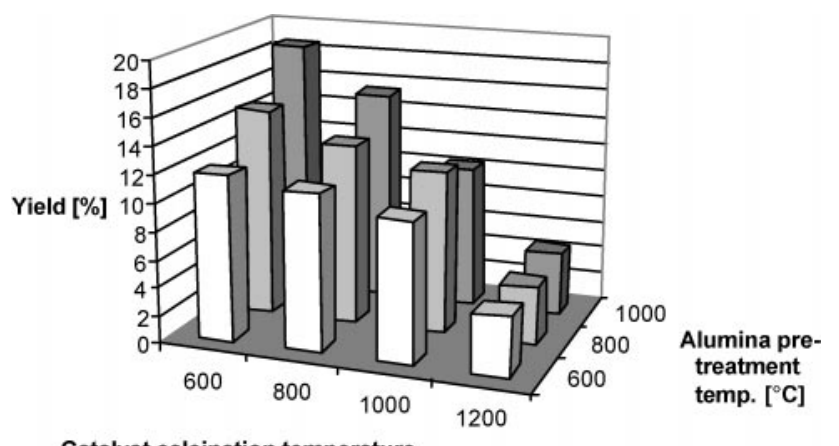

Catalyst calcination temperature

$\left[{ }^{\circ} \mathrm{C}\right]$

FIG . 2. Y ield of propene during the second cycle of propane dehydrogenation by a series of 1 wt\% Cr chromia/alumina catalysts in which the alumina pretreatment and catalyst calcination temperature were varied. 
Calcination at $1200^{\circ} \mathrm{C}$ strongly deactivated all the catalysts (propene yield of approximately $4 \%$ ), but some activity remained, since pure alumina pretreated at $1200^{\circ} \mathrm{C}$ gave a propene yield of $0.5 \%$. XPS investigation showed that the amount of $\mathrm{Na}$ present in the samples was close to the detection limit and no accumulation had occurred onto the sample surface during the heat treatment. Loss of activity thus cannot be explained by diffusion of $\mathrm{Na}$ to block the active sites. Conversionwise there was practically no difference between the catalysts prepared on different aluminas; selectivity was generally higher (up to about $80 \%$ ) the higher the alumina pretreatment temperature. The catalyst prepared on alumina pretreated at $600^{\circ} \mathrm{C}$ suffered the least deactivation when calcined at temperatures up to $1000^{\circ} \mathrm{C}$. This could be due to the fact that chromium inhibits the transformation of alumina from $\gamma$ to $\alpha$ phase (21). Indeed, peaks of $\alpha$-alumina were observed in the $\mathrm{X}$-ray diffractograms of catalysts calcined at $1200^{\circ} \mathrm{C}$, but their intensity was smaller the lower the alumina pretreatment temperature.

UV-vis DR spectra were recorded continuously in situ during the catalytic experiments. A s an example, we discuss the spectra of two chromia/alumina catalysts, which were both prepared on alumina pretreated at $600^{\circ} \mathrm{C}$, but the calcination temperatures were 600 and $1200^{\circ} \mathrm{C}$. The former is here referred to as the "fresh catalyst" and the latter as the "deactivated catalyst." The spectra of these catalysts measured during three consecutive dehydrogenationoxidation cyclesare shown in Fig. 3. A common feature of all the spectra measured at the end of oxidation was that there was an absorption band centered at $25,000-26,000 \mathrm{~cm}^{-1}$, which was due to $\mathrm{Cr}^{6+}(22)$. The $\mathrm{Cr}^{6+}$ present in the fresh catalyst was readily reduced to $\mathrm{Cr}^{3+}$ during the first $30 \mathrm{~s}$ of propane on stream, in accord with the observations of $\mathrm{H}$ akuli et al. (20) which were made by a rapid Fourier transfer infrared analysis of the gas phase products. For the deactivated catalyst in all cycles and for the fresh catalysts in the second and third cycles, $\mathrm{Cr}^{6+}$ was not stable during the helium flush but converted to $\mathrm{Cr}^{3+}$. This was evidenced by the appearance of two absorption bands at about 16,000 and $23,000 \mathrm{~cm}^{-1}$ (23). D uring the propane feed, coke was formed on the fresh catalyst, as evidenced by increasing intensity in the whole wavenumber range of the spectrum, and by that the yield of propane decreased from $13 \%$ to $12 \%$ during $13.1 \mathrm{~min}$ on stream. The presence of coke can be seen in UV-vis D R spectra because polycyclic aromatic structures have wide absorption bands in the U V-vis region $(24,25)$. D arkening of the sample through coke formation also may increase the overall intensity, leading to poorer resolution of the spectra. $\mathrm{O} n$ the deactivated catalyst, coke

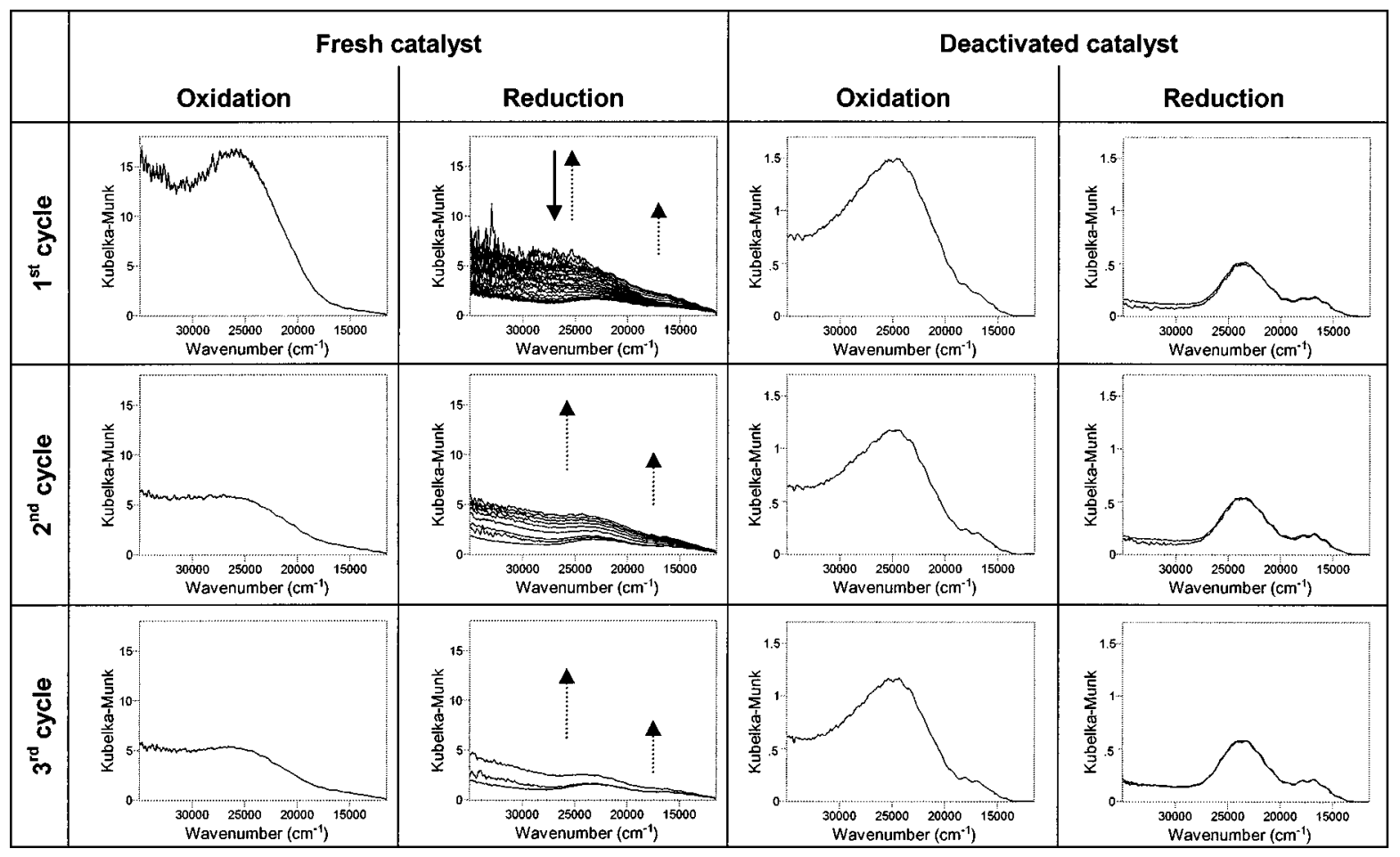

FIG. 3. U V-vis diffuse reflectance spectra of a fresh and a deactivated chromia/alumina catalyst (alumina pretreatment and catalyst calcination temperatures $600^{\circ} \mathrm{C} / 600^{\circ} \mathrm{C}$ and $600^{\circ} \mathrm{C} / 1200^{\circ} \mathrm{C}$, respectively) measured for three successive oxidation-dehydrogenation cycles (580 ${ }^{\circ} \mathrm{C}$, 1 atm) after calcination and during a 20 min propane feed. The solid-line arrow indicates the fast changes taking place during the reduction of $\mathrm{Cr}^{6+}$ to $\mathrm{Cr}{ }^{3+}$ during the first 30 s on stream, and the dotted-line arrow indicates slower changes caused by coke formation. (N ote that the $y$ scales differ for the fresh and deactivated catalyst.) 
formation as seen by U V -vis was almost negligible. D uring the following oxidative regeneration, the overall intensity decreased as a result of coke burn-off, and the $\mathrm{Cr}{ }^{6+}$ signal reappeared. H owever, it never reached its original intensity during the 40-min oxidation. O xidation of $\mathrm{Cr}^{3+}$ to $\mathrm{Cr}^{6+}$ thus seems to be a considerably slower process than reduction of $\mathrm{Cr}^{6+}$ to $\mathrm{Cr}^{3+}$.

The UV-vis DR spectra can be used to investigate the changes that have taken place during the deactivation procedure. The positions of the absorption bands are characteristic of the coordination environment of $\mathrm{Cr}^{3+}$ (23). For spectra measured at room temperature, $\mathrm{Cr}^{3+}$ located inside an $\alpha$-alumina structure (i.e., ruby) has $d$ - $d$ transitions at 18,150 and $24,700 \mathrm{~cm}^{-1}(23)$, whereas $\mathrm{Cr}^{3+}$ in $\mathrm{Cr}_{2} \mathrm{O}_{3}$ has bands at 16,600 (26) and $21,700 \mathrm{~cm}^{-1}$ (27). A ccording to our measurements, increasing the measurement temperature from room temperature to $580^{\circ} \mathrm{C}$ shifts the maximum position of the bands at about 17,000 and $22,000 \mathrm{~cm}^{-1}$ to lower energy by about 700 and $200 \mathrm{~cm}^{-1}$, respectively. The apparent band maxima at the start of the propane feed for the different catalysts are shown in Fig. 4. The energy of the $d-d$ transitions of $\mathrm{Cr}^{3+}$ increased with increasing calcination temperature. Taking into account the effect of temperature on the band maxima, the shift in absorption band maxima indicates that most of the $\mathrm{Cr}^{3+}$ present in the catalyst deactivated at $1200^{\circ} \mathrm{C}$ had been incorporated in alumina, which explains the low activity observed. We propose that the $\mathrm{Cr}^{3+}$ species with bands at about 16,000 and $23,000 \mathrm{~cm}^{-1}$ (as measured at $580^{\circ} \mathrm{C}$ ) were active dehydrogenation sites. It needs to be noted that the U V-vis DR results did not provide an explanation for the high activity of catalysts prepared on alumina pretreated at $1000^{\circ} \mathrm{C}$.

Previously, the activity of supported chromia catalysts were investigated in isobutane dehydrogenation at 350 to $500^{\circ} \mathrm{C}(15)$. The catalysts were monitored in situ by UVvis DR spectroscopy in a Praying Mantis DR attachment (Harrick) equipped with a photomultiplier detector. The performances and requirements of the two setups are compared in Table 1. The main advantage of the current fiberoptic setup compared with the Praying $M$ antis setup is the speed of data collection: fast processes with the time scale

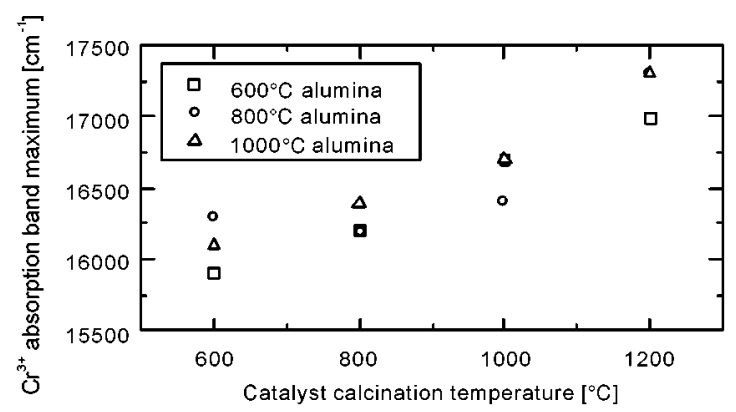

FIG . 4. A pparent absorption maximum of $\mathrm{Cr}^{3+}$ at the start of the second dehydrogenation cycle for the series of alumina pretreated at different temperatures.

\section{TABLE 1}

\begin{tabular}{|c|c|c|}
\hline & $\begin{array}{l}\text { Fiberoptic } \\
\text { setup }^{a}\end{array}$ & $\begin{array}{l}\text { Praying } M \text { antis } \\
\text { setup }(13,15)\end{array}$ \\
\hline $\begin{array}{l}\text { Time needed to acquire a } \\
\text { spectrum (200-800 nm) }\end{array}$ & $<1 \mathrm{~s}$ & $\sim 60 \mathrm{~s}$ \\
\hline $\begin{array}{l}\text { D ifferent parts of the spectrum } \\
\text { represent the same time }\end{array}$ & Yes & $\mathrm{No}^{b}$ \\
\hline R eactor requirements & $\begin{array}{l}\text { Catalytic fixed- } \\
\text { bed reactor }\end{array}$ & O ptical in situ cell \\
\hline Temperature limitation & $580^{\circ} \mathrm{C}^{c}$ & $500^{\circ} \mathrm{C}^{d}$ \\
\hline
\end{tabular}

$a$ This work.

${ }^{b}$ A photomultiplier detector records one wavelength at a time.

${ }^{c} \mathrm{D}$ egradation of probe quality was observed after use of some months.

${ }^{d}$ M aximum reported temperature.

of seconds can be followed through the use of a photo diode array detector. N ote also that through the use of a catalytic fixed-bed reactor the conversion level isnot limited because of the spectroscopic requirements; high dehydrogenation conversions could be obtained in this work (conversion up to $24 \%$ in this study vs typically below $2 \%$ in (15)).

\section{CONCLUSIONS}

The activity and selectivity of chromia/alumina catalysts increased when alumina pretreatment temperature was increased from 600 to $1000^{\circ} \mathrm{C}$, perhaps because of the increased amount of $\theta$-alumina in the samples. Calcination of the catalysts at $1200^{\circ} \mathrm{C}$ resulted in severe deactivation. O ptical fiber UV-vis D R spectroscopy indicated that $\mathrm{Cr}^{6+}$ reduced to $\mathrm{Cr}^{3+}$ during the first 30 s of propane on stream, and this was followed by coke formation. The $\mathrm{Cr}^{6+}$ formed during oxidative regeneration was not stable during an inert flush of the system but converted to $\mathrm{Cr}^{3+}$ even before the start of the propane feed. A correlation was observed between the dehydrogenation activity and $\mathrm{Cr}^{3+}$ absorption maxima for catalysts prepared on alumina pretreated at a constant temperature.

M onitoring the changes taking place in the coordination environment and oxidation state of supported metal oxides under reaction conditions was successful by optical fiber $U \mathrm{~V}$-vis DR spectroscopy. This technique is generally applicable to transition metal ions, which possess absorption bands in the U V-vis region. I ts strength lies in the possibility of using a simple catalytic fixed-bed reactor. M oreover, a photo diode array detector enables a data collection speed in the range of seconds.

\section{ACK NOWLE D G MENTS}

This work was supported by the A cademy of Finland through the Graduate School in Chemical Engineering (GSCE), the Fonds voor Wetenschappelijk Onderzoek-Vlaanderen (FWO), and the 
Geconcerteerde Onderzoeksactie (GOA) of the Flemish Government. A ssistance by $\mathrm{H}$ ugo Leeman and $\mathrm{K}$ athleen Vanrusselt is acknowledged. We thank A d M ens ( $U$ trecht U niversity) for the X PS measurements and A . O uti I. K rause (H elsinki U niversity of Technology) for valuable discussions.

\section{REFERENCES}

1. Jacoby, M., Chem. Eng. N ews M ay 4, 41 (1998).

2. Thomas, J. M ., A ngew. Chem. Int. E d. 38, 3589 (1999).

3. Topsoe, H., Stud. Surf. Sci. Catal. 130, 1 (2000).

4. Lercher, J. A., Veefkind, V., and Fajerweg, K., Vibrat. Spectrosc. 19, 107 (1999).

5. M estl, G., J. M ol. Catal. A 158, 45 (2000).

6. Wachs, I. E., Top. Catal. 8, 57 (1999).

7. N iemantsverdriet, J. W., and D elgass, W. N., Top. Catal. 8, 133 (1999).

8. H aw, J. F., Goguen, P. W., X u, T., Skloss, T. W., Song, W., and Wang, Z., A ngew. Chem. Int. E d. 37, 948 (1998).

9. H unger, M., Schenk, U., Seiler, M ., and Weitkamp, J., J. M ol. Catal. A 156, 153 (2000).

10. Stockenhuber, M., H udson, M. J., and Joyner, R. W., J. P hys. Chem. B 104, 3370 (2000).

11. Thomas, J. M., Sankar, G., Klunduk, M. C., A ttfield, M. P., M aschmeyer, T., Johnson, B. F. G., and Bell, R. G., J. Phys. Chem. B 103, 8809 (1999).

12. R essler, T., Timpe, O., N eisius, T., Find, J., M estl, G., D ieterle, M ., and Schlögl, R., J. Catal. 191, 75 (2000).

13. Bensalem, A ., Weckhuysen, B. M ., and Schoonheydt, R. A ., J. Phys. Chem. B 101, 2824 (1997).
14. M elsheimer, J., M ahmoud, S. S., M estl, G., and Schlögl, R ., C atal. L ett. 60, 103 (1999).

15. Weckhuysen, B. M., Verberckmoes, A . A ., D ebaere, H., O oms, K., Langhans, I., and Schoonheydt, R. A., J. Mol. Catal. A 151, 115 (2000).

16. B acci, M ., B aldini, F., Carla, R ., and Linari, R ., A ppl. Spectrosc. 45, 26 (1991)

17. O no, K., K anda, M., H iramoto, J., Y otsuya, K., and Sato, N., A ppl. Opt. 30, 98 (1991).

18. Cho, J., G emperline, P. J., A Idridge, P. K., and Sekulic, S. S., A nal. Chim. A cta 348, 303 (1997).

19. Buonomo, F., Sanfilippo, D., and Trifirò, F., in " $\mathrm{H}$ andbook of H eterogeneous Catalysis" (G. E rtl, H. Knözinger, and J. Weitkamp, E ds.), Vol. 5, pp. 2140-2151. V CH, Weinheim, 1997.

20. Hakuli, A ., Kytökivi, A ., Krause, A . O. I., and Suntola, T., J. Catal. 161, 393 (1996).

21. Simon, A ., van der Pol, A ., R eijerse, E. J., Kentgens, A. P. M ., van M oorsel, G.-J. M . P., and de B oer, E ., J. Chem. Soc., Faraday Trans. 91, 1519 (1995).

22. L ever, A . B. P., "Inorganic E lectronic Spectroscopy," 2nd ed., p. 326. E Isevier, A msterdam, 1984.

23. B urns, R. G., "M ineralogical A pplications of Crystal Field Theory," 2nd ed. Cambridge U niv. Press, Cambridge, U K 1993.

24. B anwell, C. N., and M cC ash, E . M ., "Fundamentals of M olecular Spectroscopy," M cG raw-H ill, N ew York, 1994.

25. K ellner, R ., M ermet, J. M ., O tto, M., Widmer, H . M ., E ds. "A nalytical Chemistry," Wiley-V CH, Weinheim, 1998.

26. R einen, D., Struct. B onding 6, 30 (1969).

27. Weckhuysen, B. M., De Ridder, L. M., and Schoonheydt, R. A., J. Phys. Chem. 97, 4756 (1993). 